\title{
Acuña, J. K., Sánchez, E. Cotidianidad, educación y violencia en el estado de Guerrero: otras prácticas y haceres en un mundo turbulento. Ciudad de México: Ediciones del libro, 178 pp.
}

\author{
Adilene Velázquez-Aguilar ${ }^{1}$ \\ Universidad Hipócrates, México. \\ https://orcid.org/0000-0003-1593-4570
}

DOI: https://doi.org/10.35622/j.rep.2021.02.005

\section{Recibido 02/12/2020/ Aceptado 20/03/2021}

En las siguientes líneas se hará un breve análisis sobre las distintas investigaciones realizadas por los profesores J. Kenny Acuña Villavicencio y Ever Sánchez Osorio y otros colegas en torno al mundo tan turbulento en el cual se encuentra Guerrero. Comenzaré hablando del primer apartado: La Escuela y las Formas de/Miedo, donde nos precisan los autores cómo la vida cotidiana ha cambiado completamente en nuestro estado. Ellos dejan muy en claro la urgencia de crear una escuela creativa que realmente enseñe el desarrollo de competencias, habilidades y valores que permitan al sujeto a ser capaces de enfrentar y construir un mundo distinto al que actualmente se vive.

En cuanto al segundo apartado, La escuela y la necropolítica del trabajo en el estado de Guerrero, los autores indican que la educación en el estado de Guerrero es alarmante debido a la relación compleja que existe entre el Estado, el crimen organizado y el capital. Asimismo, señalan que la escuela debe ser el punto de partida para reorganizar la vida cotidiana y restablecer la dominación social y económica, esto es, generar nuevos sujetos educados e independientes de una forma "Estado del terror". Es por ello que deben elaborar programas, categorías y sentidos pedagógicos en el sentido de crear una formación más humana y crítica con su hacer y creatividad. La administración de la muerte tal como lo plantea este libro, está pensada como una forma de política de negación a la desigualdad presente en muchas regiones de la sociedad guerrerense. Mucho de ello tiene que ver con el devenir histórico y las ideologías que a lo largo del tiempo como han sido partícipes de la creación y conformación compleja de la anatomía social y política. Prueba de ello los jóvenes guerrerenses, quienes adolecen de una educación creativa, han sido obligados a formar parte de las economías informales. Ante ello surge y urge la necesidad de cuestionar el papel que está teniendo el Estado en el control del trabajo bajo las dinámicas de una economía de mercado que se mueve en los intersticios de la violencia y la necropolítica.

El apartado: Violencia y miedo en Acapulco, comienza diciendo que el puerto de Acapulco es un lugar donde los últimos años ha sido asechado brutalmente por la inseguridad, la violencia delincuencial y donde el estado ha sido rebasado por la delincuencia organizada y la impunidad. El estado de Guerrero se caracteriza por ser un estado "bronco" marcado por

\footnotetext{
${ }^{1}$ Lic. en educación secundaria con especialidad en español en la Normal Superior del Estado de Morelos, egresada de la Maestría en Ciencias de la Educación de la Universidad Hipócrates en la Ciudad y Puerto de Acapulco. Actualmente laboro como Supervisora encargada de Escuela Secundaria Técnica Zona 02 (12FZT0002T). Las líneas de investigación son: educación, pedagogía y didáctica. Correo electrónico: ayi_chivita@ hotmail.com
} 
la marginalidad socioeconómica, la violencia política, el caciquismo, la corrupción, la impunidad y la delincuencia. A partir de esto surgen muchas interrogantes y una de ellas es ¿Cómo pudimos llegar a vivir en un país lleno de temor, de actividades ilícitas y violencia? Nos damos cuenta que la corrupción y la impunidad hizo que los jóvenes no tengan esperanzas, exista una mayor marginación y falta de empleo. La impunidad es otro factor fundamental en este proceso, debido a que la mayor parte de la sociedad se siente huérfana y desprotegida de la justicia. Dicho esto, debemos de partir de una meta en colegiado centrada principalmente en la reconstrucción del tejido social, generar opciones de trabajos dignos con salarios justos, mejorar el sistema de procuración de justicia, incursionar en la regularización del uso, construir un sistema de seguridad nacional eficiente, brindar importancia al sistema educativo y, a su vez, generar en la sociedad en general la importancia de denunciar los delitos de los cuales hayan sido víctimas.

La Morfología de la muerte en Acapulco, otro de los apartados del libro que se comenta, recalca que las cifras de muertes violentas en Acapulco es el principal indicador en la medición de la violencia que ahí se vive, pero la gran interrogante y aquella que nos genera mayor inquietud y controversia es saber, ¿cuáles son las principales causas de la violencia y muerte? Es triste darnos cuenta cómo a través del miedo han podido gestionar el poder, los recursos y el territorio. Con esto nos encontramos ante la presencia de grupos sin escrúpulo alguno que dominan territorios y negocios rentables sin importan el alto precio que la sociedad guerrerense y a nivel nacional se tenga que pagar.

En el siguiente apartado: La disciplina y los rudimentos de la paz desde el aula, se enfatiza el tema de la violencia escolar, es decir, la disciplina, control y poder en la interacción en el aula. La violencia escolar es considerada como un problema de convivencia social que impide por múltiples razones un normal desarrollo del proceso enseñanza-aprendizaje en las aulas y que contamina la interacción de los distintos actores educativos que conforman un espacio escolar. Por ello es importante mencionar el papel fundamental que la disciplina positiva ejerce dentro del aula, ya que esta es indispensable para el desarrollo de un ambiente educativo saludable, armonioso y capaz de funcionar activamente.

La escuela como una institución de orden social visualiza la disciplina como un punto de encuentro beneficioso en la negociación y puesta en común de las metas y objetivos educativos, generando mayor cercanía en la interacción docentealumno, beneficiando así el control, la autorregulación y un desempeño social más propicio. Furlan (2003) considera que la disciplina escolar es una de las tareas que el docente debe realizar con éxito, ya que favorece la disposición para la clase y coincide con la perspectiva de un punto de encuentro. Muchas veces la violencia escolar es justificada como una situación normal al verse como un método de disciplina, por ello es importante que se analice el uso de ciertas reglas en el salón de clases desde un principio y que éstas sean establecidas en consenso con los distintos actores educativos. Esto a fin de que en ningún momento se sobrepase la línea de la disciplina positiva y del abuso de los derechos humanos. Por ello, es indispensable moverse en el plano del "ser" y "deber ser", estableciendo el fortalecimiento de conductas basadas en valores, motivación por generar nuevos conocimientos, asistencia regular a las aulas de clases, integración a un medio escolar sano.

El apartado Trascendiendo el Conflicto en un Contexto de Violencia. Educación para la Ciudadanía, señala que el propósito primordial del sistema educativo en México es brindar una educación laica, gratuita y de calidad. Es por ello que en la actualidad los docentes dentro de las aulas se enfrentan a la necesidad de poder construir educandos que sean capaces de alcanzar su máximo potencial tal como lo demanda nuestro mundo actual. Es decir, personas que tengan la motivación y capacidad de lograr su desarrollo en un ámbito personal, laboral y familiar, dispuestas a mejorar su entorno social y natural, así como a continuar aprendiendo a lo largo de la vida, aún en medio de un mundo tan complejo lleno de violencia, muerte y desempleo. Sin duda alguna es necesario formar a los estudiantes en lo afectivo con la finalidad de que la escuela trascienda en la vida de los estudiantes y les permita una inserción exitosa en la vida actual. Por otro lado, debemos afrontar de manera comprometida, responsable, equitativa y justa para desafiar de forma positiva situaciones complejas dentro y fuera del ámbito escolar. 
El mundo en general y en especial nuestro estado de Guerrero carece de valores ciudadanos. Por lo menos, es lo que dice el autor del apartado: Rudimentos para la formación de agencia democrática y paz positiva en el estado de Guerrero; educación para la democracia, quien sostiene que los retos que hoy en día poseemos como actores educativos es sin duda alguna: a) generar un cambio en la forma cómo se percibe el mundo; b) hacer sujetos más informados, democráticos, activos participativos e inmersos en la toma de decisiones; c) capacitar a los futuros ciudadanos para que puedan participar activamente en la sociedad civil y política sin riesgo de exclusión; y, c) asegurar que todos ellos adquieran aquellas virtudes, conocimientos y habilidades necesarias para la participación política y la inserción social.

En el último apartado: Unisur. Una experiencia de educación comunitaria, podemos darnos cuenta de la gran aportación y análisis de experiencias de los docentes de la Universidad de los Pueblos del Sur que los autores nos hacen saber. Ellos cuestionan la formación académica deficiente que existe en Guerrero y las penetrantes condiciones de pobreza que atraviesan la mayoría de los pueblos sobre todo en las comunidades indígenas. Estas circunstancias afectan sobre todo a todos aquellos jóvenes que desean seguir preparándose. Las escuelas no cuentan con las condiciones educativas básicas para hacer permanecer a los educandos y a evitar que abandonen las escuelas en las zonas rurales se hace presente. Estos factores, entre otros, son la explicación de que el acceso a una educación de excelencia para las poblaciones rurales de nuestro estado sea ostensiblemente más precario que del resto de las zonas urbanas. Es por ello que hablar de la educación Superior en estos contextos es ya una historia de logro. Lo que hace que las condiciones de los habitantes de estas zonas sean muy bajas, y que la mayoría de sus habitantes se dediquen al desarrollo de actividades primarias agrícolas y ganaderas. Teniendo en claro las condiciones políticas, sociales, contextuales, económicas, culturales y, sobre todo educativas, los docentes de UNISUR generan y plasman aportes importantes encaminados al reforzamiento de la formación académica de los estudiantes con base en la experiencia y el respeto a la diferencia humana. 